\title{
Examining a Transition from Supramolecular Halogen Bonding to Covalent Bonds: Topological Analysis of Electron Densities and Energies in the Complexes of Bromosubstituted Electrophiles
}

\author{
Daniel K. Miller, Cody Loy, and Sergiy V. Rosokha*
}

Cite This: ACS Omega 2021, 6, 23588-23597

Read Online

ABSTRACT: The transition from weak (noncovalent) interactions to fully developed covalent bonds is examined using the quantum theory of atoms in molecules in a series of halogen-bonded (XB) complexes of bromosubstituted electrophiles, $\mathrm{RBr}$, with 1,4-diazabicyclo[2.2.2] octane (DABCO) and $\mathrm{Cl}^{-}$and $\mathrm{Br}^{-}$anions. The gradual decrease in the $\mathrm{XB}$ lengths in these associations, $d_{\mathrm{Br} \cdots \mathrm{Y}}$ (where $\mathrm{Y}=\mathrm{Cl}^{-}, \mathrm{Br}^{-}$, or $\mathrm{N}$ ), was accompanied by the exponential increase in the binding energies and charge transfer, as well as electron densities and magnitudes of the kinetic and potential energy densities at the bond critical points (BCPs) on the $\mathrm{Br} \cdots \mathrm{Y}$ bond path. These indices, as well as characteristics of the adjacent

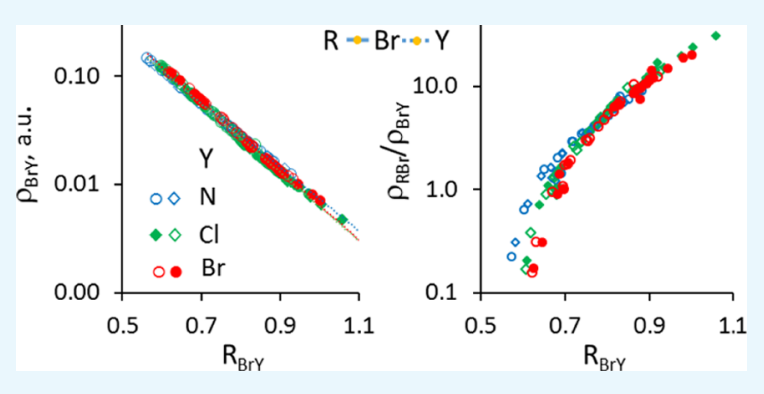
bonds in the $\mathrm{XB}$ donor, followed remarkably close trend lines when plotted against the normalized XB length $R_{\mathrm{BrY}}=d_{\mathrm{Br} \cdots \mathrm{Y}} /\left(r_{\mathrm{Br}}+r_{\mathrm{Y}}\right)$ (where $r_{\mathrm{Br}}$ and $r_{\mathrm{Y}}$ are the van der Waals radii) regardless of the methods [MP2/6-311+G(d,p) or M062X/6-311+G(d,p)], media (gas phase or dichloromethane), and nucleophiles $\left(\mathrm{Cl}^{-}, \mathrm{Br}^{-}\right.$, or $\left.\mathrm{DABCO}\right)$. In the systems with an $R_{\mathrm{BrY}}$ higher than about 0.78 , the energy densities $H(\mathbf{r})$ at BCPs at the $\mathrm{Br} \cdots \mathrm{Y}$ bond path were small and positive, and XBs did not substantially affect the characteristics of the adjacent $\mathrm{R}-\mathrm{Br}$ covalent bond in the $\mathrm{XB}$ donor. Accordingly, the $\mathrm{XB}$ can be identified as noncovalent in this range. In the complexes with $R_{\mathrm{BrY}}$ values between about 0.67 and 0.78 , energy densities $H(\mathbf{r})$ at $\mathrm{Br} \cdots \mathrm{Y}$ BCPs were negative, and their magnitudes increased with the decrease in the $\mathrm{Br} \cdots \mathrm{Y}$ separation. In this range, formation of $\mathrm{XBs}$ was accompanied by the increase in the $\mathrm{R}-\mathrm{Br}$ bond length in the $\mathrm{XB}$ donor and the decrease in the magnitude of the (negative) $H(\mathbf{r})$ values at the BCPs of the R-Br bonds. XBs can be classified as partially covalent in this $R_{\mathrm{BrY}}$ range. At an $R_{\mathrm{BrY}}$ less than about 0.67 , electron densities were larger, and energy densities were more negative at BCPs of the $\mathrm{Br} \cdots \mathrm{Y}$ bond than those at $\mathrm{BCPs}$ of the $\mathrm{R}-\mathrm{Br}$ bond in the $\mathrm{XB}$ donor. This indicates that $\mathrm{Br} \cdots \mathrm{Y}$ bonds were stronger than $\mathrm{R}-\mathrm{Br}$ bonds, and these $(\mathrm{Br} \cdots \mathrm{Y}) \mathrm{XBs}$ can be regarded as essentially covalent. The synchronous change of a variety of $(\mathrm{R}-\mathrm{Br}$ and $\mathrm{Br} \cdots \mathrm{Y})$ bonding characteristics with $R_{\mathrm{BrY}}$ suggests that the normalized $\mathrm{XB}$ bond length can be used as a basic parameter in the identification of the type of intermolecular interaction. A continuity of these characteristics suggests an inherent relationship between limiting (covalent and noncovalent) types of XBs and thus an onset of molecular-orbital interactions in the weaker bonds.

\section{INTRODUCTION}

Halogen bonding $(\mathrm{XB}) \mathrm{R}-\mathrm{X} \cdots \mathrm{Y}$, an attraction of electron-rich species (Y) to an electrophilic halogen atom (X) that is covalently bonded to a group or an atom (R), has emerged during the last 2 decades as one of the most important supramolecular interactions. ${ }^{1,2}$ A number of publications demonstrated that such bonding can be fruitfully applied in various areas including crystal engineering of useful materials, molecular recognition, catalysis of organic reactions, and rational drug design. ${ }^{1-8}$ These applications are facilitated by the combination of $\mathrm{XB}$ directionality with the possibility of the wide-range tuning of its strength via variations of the nature of the nucleophile $(\mathrm{Y})$, halogen atom $(\mathrm{X})$, and a group or an atom (R). Indeed, the crystallographic literature contains examples of the $\mathrm{XB}$ associations with interatomic distances ranging from the corresponding van der Waals separations to those which are within $15-20 \%$ of the relevant fully developed covalent bond. ${ }^{1,2,9-15}$ This raises questions about the relationship and distinctions between such diverse bonds and boundaries between supramolecular and covalent bonding, as well as the nature of $\mathrm{XB}$ and its relation to a covalent bond.

Bader's quantum theory of atoms in molecules (QTAIM) provides a powerful methodology to classify and to quantify intermolecular interactions through the analysis of the topology of the electron density $\rho(\mathbf{r})$ in molecules and supramolecular associations. ${ }^{16-18}$ This analysis is focused on the points in space between interacting species (atoms or a

Received: July 15, 2021

Accepted: August 19, 2021

Published: September 3, 2021 
group of atoms) at which the first derivatives of the density with respect to each of the three coordinates vanish [i.e., $\nabla \rho(\mathbf{r})=0]$ and which are characterized by two negative and one positive eigenvalues of the Hessian matrix of the partial second derivatives of $\rho(\mathbf{r})$ (saddle points). Such points usually suggest the existence of bonding between the atoms. ${ }^{16-19}$ Therefore, they are referred to as $(3,-1)$ and/or bond critical points (BCPs). The characteristics of BCPs, including the magnitude of density $\rho(\mathbf{r})$, the Laplacian, $\nabla^{2} \rho(\mathbf{r})$, kinetic energy and potential energy densities $G(\mathbf{r})$ and $V(\mathbf{r})$, and energy density $H(\mathbf{r})=G(\mathbf{r})+V(\mathbf{r})$, allowed assignments of the bonding ranging from the shared-shell (SS) covalent to weak closed-shell (CS) noncovalent interactions. ${ }^{18,20}$

The QTAIM analysis of the topology of the electron density was used for the detection and classification of intermolecular bonding in various supramolecular associations. ${ }^{20-31}$ The majority of relevant studies were focused on hydrogen bonding, which is arguably the most important and wellstudied supramolecular interaction. ${ }^{20-24}$ Based on the topological and energetic properties of the electron density distribution for the hydrogen $(\mathrm{H} \cdots \mathrm{F})$ bond in the wide range of $\mathrm{H} \cdots \mathrm{F}$ separation from 0.8 to $2.5 \AA$, Espinosa et al. established three characteristic regions representing different interaction states. ${ }^{20}$ The extreme regions in the bond length variations were associated with pure CS and SS interactions, while the middle region involves the formation of the bonding molecular orbital. ${ }^{20}$ Such a study of the topological and energetic properties of $\rho(\mathbf{r})$ at BCPs in the full range of intermolecular interactions, especially those in the SS $\leftrightarrow$ CS transition region, could help clarify fundamental questions of chemical bonding and reactivity, for example, proton transfer and resonant-assisted hydrogen bonding. ${ }^{20} \mathrm{~A}$ similar full-range analysis of the variations of the topological properties of the electron density and energy at halogen bonds' BCPs could provide information about the nature and properties of XBs, as well as assist in the elucidation of the halogen transfer mechanism and other reactions of halogenated molecules. Nevertheless, while the QTAIM characterization of many (weak and strong) $\mathrm{XB}$ complexes is available in the literature, ${ }^{26-28}$ the comparable full-range analysis of the $\mathrm{XB}$ systems is lacking.

In the current work, we present the QTAIM analysis of the electron density topology for $\mathrm{XB}$ complexes of bromosubstituted electrophiles $\mathrm{RBr}$ (Chart 1) with 1,4diazabicyclo[2.2.2] octane (DABCO) and $\mathrm{Cl}^{-}$and $\mathrm{Br}^{-}$anions.

Chart 1. Structures of $\mathrm{R}-\mathrm{Br}$ Electrophiles $(\mathrm{X}=\mathrm{H}, \mathrm{F}, \mathrm{Br}$, $\mathrm{CN}, \mathrm{NO}_{2}, \mathrm{CONH}_{2}, \mathrm{COCBr}_{3}$, etc.)<smiles>O=C1CCC(=O)N1Br</smiles>

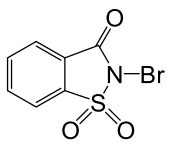

BrSAC

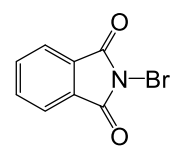

BrPIM

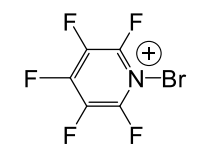

$\mathrm{F}_{5} \mathrm{Pyr}-\mathrm{Br}^{+}$
This study is based on the results of our previous studies, ${ }^{13-15}$ which demonstrated that the $\mathrm{RBr} \cdots \mathrm{Y}$ (where $\mathrm{Y}$ $=\mathrm{Br}, \mathrm{Cl}$, or $\mathrm{N}$ ) separations measured in the solid-state associations varied gradually from the values close to van der Waals separations to that of the fully developed covalent bond (Table 1).

Structural and thermodynamic characteristics of these complexes were reproduced reasonably well by quantum-
Table 1. Summary of the $\mathrm{R}_{\mathrm{Br} \cdots \mathrm{D}}$ Distances (in $\AA$ ) Measured in the XB Solid-State Associations of RBr Electrophiles with DABCO, $\mathrm{Br}^{-}$, or $\mathrm{Cl}^{-}$Nucleophiles ${ }^{a}$

\begin{tabular}{llll}
\multicolumn{1}{c}{$\mathrm{RBr}$} & \multicolumn{1}{c}{$d_{\mathrm{Br} \cdots \mathrm{N}}{ }^{b}$} & \multicolumn{1}{c}{$d_{\mathrm{Br} \cdots \mathrm{Cl}}{ }^{c}$} & \multicolumn{1}{c}{$d_{\mathrm{Br} \cdots \mathrm{Br}}{ }^{d}$} \\
$\mathrm{CH}_{2} \mathrm{Br}_{2}$ & N/A & 3.191 & 3.314 \\
$\mathrm{C}_{6} \mathrm{Br}_{2} \mathrm{~F}_{4}$ & $2.891-2.894$ & 3.169 & N/A \\
$\mathrm{C}_{2} \mathrm{Br}_{2} \mathrm{~F}_{4}$ & 2.829 & N/A & N/A \\
$\mathrm{CHBr}_{3}$ & 2.877 & N/A & 3.588 \\
$\mathrm{CBr}_{3} \mathrm{CONH}{ }_{2}$ & 2.772 & $3.046-3.277$ & $3.182-3.252$ \\
$\mathrm{CBr}_{3} \mathrm{~F}$ & $2.654-2.764$ & $3.082-3.173$ & $3.171-3.257$ \\
$\mathrm{CBr}_{3} \mathrm{COCBr}$ & N/A & $3.031-3.206$ & $3.121-3.251$ \\
$\mathrm{CBrCl}_{3}$ & $2.714-2.732$ & 3.143 & 3.309 \\
$\mathrm{CBr}_{4}$ & $2.726-2.735$ & $3.065-3.243$ & $3.154-3.352$ \\
$\mathrm{CBr}_{3} \mathrm{CN}$ & N/A & $3.098-3.134$ & $3.080-3.276$ \\
$\mathrm{CBr}_{3} \mathrm{NO}{ }_{2}$ & $2.543-2.605$ & $2.986-3.269$ & $3.141-3.2465$ \\
$\mathrm{NBrSIM}$ & $2.332-2.364$ & $2.822-2.852$ & $2.836-2.929$ \\
$\mathrm{NBrPIM}$ & $2.257-2.348$ & $2.700-2.734$ & $2.850-2.890$ \\
$\mathrm{Br}_{2}$ & $2.165-2.166$ & 2.567 & $2.525-2.563$ \\
$\mathrm{DABCO}$ & 2.130 & N/A & $2.528-2.536$
\end{tabular}

${ }^{a}$ The ranges of the bond lengths are shown if several structures and/ or several crystallographically independent bond distances in one structure are available. See Table S1 in the Supporting Information for the complete list of bond lengths and the references to the original publications. ${ }^{b}$ From ref 13 and references therein. ${ }^{c}$ From ref 15 and references therein. ${ }^{d}$ From ref 14 and references therein.

mechanical computations. ${ }^{13-15}$ Importantly, these series contain (experimental and/or calculated) complexes with characteristics covering the whole array of values, eliminating any large changes and leaving no substantial gaps between successive entries. Accordingly, they allow QTAIM analysis of the bonding in the full range of the Br..Y lengths, from weak complexes with XB lengths near the van der Waals separations to covalent bonds. The series under study included neutral and charged complexes formed by the association of a neutral or anionic nucleophile with a neutral or cationic $\mathrm{XB}$ donor. Therefore, these complexes allow the examination of the effects of the nature and charge of the $\mathrm{XB}$ donor and acceptor and identify major factors determining the characteristics of the BCPs and the nature and properties of $\mathrm{XB}$.

\section{METHODOLOGY}

Quantum-mechanical calculations were carried out using the Gaussian 09 suite of programs. ${ }^{32}$ Geometries of electrophiles and $\mathrm{XB}$ complexes between $\mathrm{RBr}$ electrophiles and $\mathrm{DABCO}$, $\mathrm{Br}^{-}$, or $\mathrm{Cl}^{-}$were optimized without constraints using two methods: MP2 calculations with the $6-311++\mathrm{G}(\mathrm{d}, \mathrm{p})$ basis set and density functional theory (DFT) calculations with the M062X functional and 6-311+G(d,p) basis set. ${ }^{33}$ The absence of the imaginary vibrational frequencies confirmed that the optimized structures represented true minima. Thus, while fully optimized complexes and nonequilibrium systems (obtained via optimization with fixed interatomic separations along the reaction coordinate) were used in the previous fullrange analyses of the hydrogen-bonded ( $\mathrm{HB}$ ) associations, the diverse series of $\mathrm{RBr}$ electrophiles utilized in the current work allowed us to obtain fully optimized complexes at their equilibrium geometries with $\mathrm{Br} \cdots \mathrm{Y}$ distances covering the whole range between the limiting types of bonding. It should be mentioned that optimizations with some of the $\mathrm{RBr}$ electrophiles produced multiple local energy minima corresponding to various types of complexes (e.g., HB complexes or 
complexes showing multipoint interactions). However, only the complexes formed via single-point $\mathrm{XB}$ between $\mathrm{RBr}$ and nucleophiles were examined in the current work.

The M062X/6-311+G(d,p) method was used in our earlier computations of $\mathrm{XB}$ complexes. ${ }^{12-15}$ Previous theoretical analyses indicated that it produces excellent geometries and energies at a reasonable computational cost. ${ }^{34,35}$ Importantly, our earlier studies demonstrated that the characteristics of the $\mathrm{XB}$ complexes between $\mathrm{RBr}$ electrophiles obtained via such computations were in good agreement with the experimental data. ${ }^{12-15}$ To verify the independence of the results on the method and basis set, the complexes were also optimized via MP2/6-311++G $(d, p)$ calculations (similar to that in the earlier QTAIM analysis of $\mathrm{HB}$ and XB complexes ${ }^{20-27}$ ). Since the characteristics of the calculated complexes involving charged species depend substantially on the medium, the complexes of $\mathrm{RBr}$ electrophiles with $\mathrm{Cl}^{-}$and $\mathrm{Br}^{-}$anions were optimized and examined in the gas phase and in dichloromethane. Calculations in dichloromethane were carried out using a polarizable continuum model. ${ }^{36}$ This moderately polar solvent represents a good media for modeling solid-state ionic compounds. ${ }^{14,15}$

Values of $\mathrm{XB}$ energies $\Delta E$ were determined using $\Delta E=$ $E_{\text {comp }}-\left(E_{\mathrm{RBr}}+E_{\mathrm{Y}}\right)+$ BSSE, where $E_{\text {comp }}, E_{\mathrm{RBr}}$, and $E_{\mathrm{Y}}$ are the sums of the electronic energy and zero-point energy (ZPE) of the complex, $\mathrm{RBr}$, and the nucleophile, respectively (all of them in the optimized geometries), and the basis set superposition error (BSSE) is the basis set superposition energy. ${ }^{37}$ Since the formation of complexes involves the deformation of $\mathrm{RBr}$ (and $\mathrm{DABCO}$ ), these values can be expressed as $\Delta E=\Delta E_{\text {strain }}+\Delta E_{\text {int }}$, where $\Delta E_{\text {int }}$ is the interaction energy between the deformed reactants. ${ }^{38}$ The $\Delta E_{\text {int }}$ values followed the same trends as those of $\Delta E$.

The QTAIM analyses of the optimized complexes were carried out with the Multiwfn program. ${ }^{39}$ The results were visualized using the molecular graphics program VMD. ${ }^{40}$ The wfn output files for such analysis were produced with Gaussian 09 via single-point calculations of the optimized complexes using the same method (MP2 or M062X) as that used for optimization.

\section{RESULTS AND DISCUSSION}

The $\mathrm{Br} \cdots \mathrm{Y}$ separations (where $\mathrm{Y}=\mathrm{N}, \mathrm{Cl}$, or $\mathrm{Br}$ ) in the $\mathrm{XB}$ complexes of $\mathrm{RBr}$ electrophiles with $\mathrm{DABCO}, \mathrm{Cl}^{-}$, or $\mathrm{Br}^{-}$ nucleophiles resulting from the MP2/6-311++(d,p) and/or DFT (M062X/6-311+(d,p)) optimizations are listed in Tables 2 and S2 in the Supporting Information. The MP2 and M062X optimizations produced highly correlated values $\left(R^{2}=0.99\right.$, Figure $S 1$ in the Supporting Information). The $\mathrm{RBr} \cdots \mathrm{Y}$ distances, $d_{\mathrm{Br} \cdots \mathrm{Y}}$, calculated with dichloromethane as a medium are somewhat higher than that obtained in the gas phase (as was observed in the other complexes of neutral XB donors with anionic nucleophiles). In the series of complexes of the same nucleophile with different $\mathrm{RBr}$ electrophiles, the variation of the calculated $d_{\mathrm{Br} \cdots \mathrm{Y}}$ values follows the same trends as those observed in the solid-state associations. The absolute values of these distances are reasonably close to the X-ray (solid-state) structures in Table 1 . They cover a whole range of interatomic separations, from distances close to the van der Waals contacts established in the complexes with $\mathrm{CH}_{3} \mathrm{Br}$ to that of the fully developed covalent bond in $\mathrm{DABCO}-\mathrm{Br}^{+}, \mathrm{Cl}-\mathrm{Br}$, and $\mathrm{Br}_{2}$ (which could be formally considered as complexes formed by
Table 2. Br...Y Separations (in $\AA$ ) in the Calculated XB Complexes of $\mathrm{RBr}$ Electrophiles with $\mathrm{DABCO}, \mathrm{Cl}^{-}$, and $\mathrm{Br}^{-}$

\begin{tabular}{|c|c|c|c|c|c|}
\hline $\mathrm{RBr}$ & $\mathrm{DABCO}^{a, b}$ & $\mathrm{Cl}^{-a, b}$ & $\mathrm{Cl}^{-a, c}$ & $\mathrm{Br}^{-b, d}$ & $\mathrm{Br}^{-c, d}$ \\
\hline $\mathrm{CH}_{3} \mathrm{Br}$ & 2.980 & 3.331 & 3.805 & 3.404 & 3.703 \\
\hline $\mathrm{CH}_{2} \mathrm{BrF}$ & 2.950 & 3.222 & 3.615 & 3.330 & 3.630 \\
\hline $\mathrm{CH}_{2} \mathrm{Br}_{2}$ & 2.859 & 3.106 & 3.516 & 3.230 & 3.494 \\
\hline $\mathrm{BrCCH}$ & 2.806 & 3.050 & 3.311 & 3.196 & 3.352 \\
\hline $\mathrm{C}_{6} \mathrm{Br}_{2} \mathrm{~F}_{4}$ & 2.754 & 2.911 & 3.296 & 3.078 & 3.365 \\
\hline $\mathrm{C}_{2} \mathrm{Br}_{2} \mathrm{~F}_{4}$ & 2.759 & 2.921 & 3.283 & 3.063 & 3.336 \\
\hline $\mathrm{CHBr}_{3}$ & 2.727 & 2.919 & 3.367 & 3.074 & 3.363 \\
\hline $\mathrm{CBr}_{3} \mathrm{CONH}_{2}$ & 2.642 & 2.832 & 3.232 & 3.020 & 3.306 \\
\hline $\mathrm{CBr}_{3} \mathrm{~F}$ & 2.662 & 2.824 & 3.218 & 2.972 & 3.288 \\
\hline $\mathrm{CBr}_{3} \mathrm{COCBr}_{3}$ & 2.595 & 2.619 & 3.131 & 2.792 & 3.249 \\
\hline $\mathrm{CBrCl}_{3}$ & 2.608 & 2.787 & 3.207 & 2.932 & 3.245 \\
\hline $\mathrm{CBr}_{4}$ & 2.583 & 2.722 & 3.188 & 2.882 & 3.268 \\
\hline $\mathrm{CBr}_{3} \mathrm{CN}$ & 2.545 & 2.657 & 3.108 & 2.808 & 3.198 \\
\hline $\mathrm{CBr}_{3} \mathrm{NO}_{2}$ & 2.554 & 2.647 & 3.097 & 2.779 & 3.189 \\
\hline $\mathrm{CBr}\left(\mathrm{NO}_{2}\right)_{3}$ & 2.516 & 2.596 & 2.962 & 2.637 & 3.016 \\
\hline BrSIM & 2.359 & 2.462 & 2.892 & 2.639 & 3.056 \\
\hline BrPIM & 2.355 & 2.443 & 2.884 & 2.616 & 3.044 \\
\hline $\mathrm{Br}_{2}$ & 2.302 & 2.450 & 2.473 & 2.581 & 2.573 \\
\hline BrSAC & 2.262 & 2.354 & 2.481 & 2.478 & 2.619 \\
\hline $\mathrm{BrCl}$ & 2.274 & 2.441 & 2.430 & 2.573 & 2.524 \\
\hline $\mathrm{BrF}$ & 2.189 & 2.430 & 2.375 & 2.591 & 2.536 \\
\hline $\mathrm{DABCO}-\mathrm{Br}^{+}$ & 2.154 & 2.308 & 2.430 & 2.449 & 2.558 \\
\hline NBr-pyrazine ${ }^{+}$ & 2.079 & 2.223 & 2.299 & 2.333 & 2.386 \\
\hline $\mathrm{F}_{5} \mathrm{Pyr}-\mathrm{Br}^{+}$ & 1.980 & 2.182 & 2.190 & 2.305 & 2.309 \\
\hline $\mathrm{Br}^{+}$ & 1.935 & 2.166 & 2.167 & 2.294 & 2.296 \\
\hline
\end{tabular}

${ }^{a}$ From MP2/6-311++G(d,p) calculations. The data obtained from the M062X/6-311+G(d,p) computations (from refs 13 and 14) are listed in Table S2 in the Supporting Information. ${ }^{b}$ In the gas phase. ${ }^{c}$ In dichloromethane. ${ }^{d}$ From M062X/6-311+G(d,p) calculations.

the $\mathrm{Br}^{+}$cation with the corresponding $\mathrm{DABCO}, \mathrm{Cl}^{-}$, or $\mathrm{Br}^{-}$ nucleophiles).

The binding energies, $\Delta E$, in the complexes under study are listed in Table S3 in the Supporting Information. The variations of their values with interatomic distances for the series of complexes of $\mathrm{RBr}$ electrophiles with different nucleophiles are illustrated in Figure 1 (with $\Delta E$ shown on a logarithmic scale). As was noted earlier for the complexes of $\mathrm{RBr}$ with $\mathrm{DABCO},{ }^{13}$ the magnitude of $\Delta E$ in the series of complexes with the same nucleophile increases roughly exponentially with the decrease in $d_{\mathrm{Br} \cdots \mathrm{Y}}$. It is noticeable, however, that the dependencies between $\ln (-\Delta E)$ and $d_{\mathrm{Br} \cdots \mathrm{N}}$ in these series show substantial scattering of points, and they are characterized by moderate values of $R^{2}$ in the $0.80-0.93$ range.

The magnitudes of the binding energies of the complexes of $\mathrm{RBr}$ with the $\mathrm{Cl}^{-}$or $\mathrm{Br}^{-}$anions calculated in dichloromethane are lower than those evaluated in the gas phase. In fact, the calculations of the complexes between the weaker electrophiles and anions in dichloromethane produce local minima with positive $\Delta E$ values, indicating that the corresponding $\mathrm{XB}$ complexes are only kinetically stable (Table S3 in the Supporting Information, note that these complexes are not shown in Figure 1 with a logarithmic energy scale). The most important for the current work is the continuum of the $\mathrm{XB}$ binding energies in the series of complexes with all nucleophiles, which vary from the values characteristic for weak complexes (or kinetically stabilized one) to that typical of covalent bonds. 


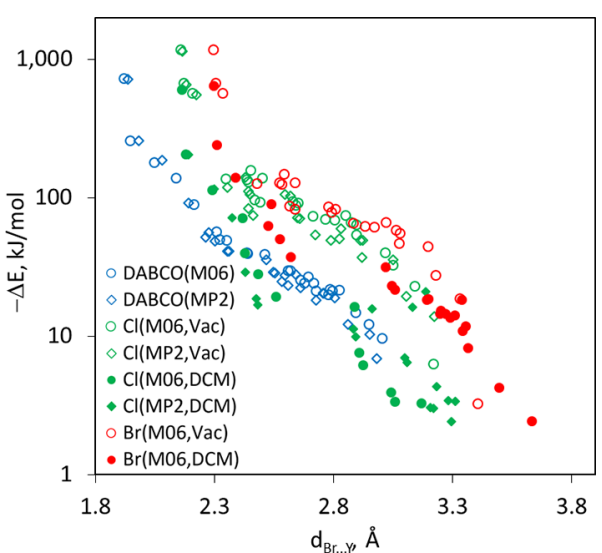

Figure 1. Dependence of the $\mathrm{XB}$ binding energies on the $\mathrm{Br} \cdots \mathrm{Y}$ separation for complexes between $\mathrm{RBr}$ electrophiles and $\mathrm{DABCO}$ (blue), $\mathrm{Cl}^{-}$(green), and $\mathrm{Br}^{-}$(red). Rhombuses and circles show values for the complexes obtained via MP2 and M062X optimizations, respectively. Filled and open symbols show values for the complexes optimized in dichloromethane and the gas phase, respectively (as indicated).

The QTAIM analysis of the optimized complexes revealed the presence of the $(3,-1) \mathrm{BCPs}$ at the $\mathrm{Br}-\mathrm{R}$ bond in the electrophiles as well as along $\mathrm{Br} \cdots \mathrm{Y}$ bond paths $\left(\mathrm{Y}=\mathrm{Cl}^{-}, \mathrm{Br}^{-}\right.$, or $\mathrm{N}$ atom of $\mathrm{DABCO}$ ) in all $\mathrm{XB}$ associations under study. Examples of these bond paths and BCPs are shown in Figure 2.

The electron density and energy characteristics at these BCPs for the series of RBr.DABCO complexes optimized via MP2 calculations are listed in Table 3. Similar characteristics for the RBr.DABCO complexes obtained via M062X computations, as well as characteristics of the complexes of $\mathrm{RBr}$ electrophiles with $\mathrm{Cl}^{-}$and $\mathrm{Br}^{-}$anions (obtained in the gas phase and dichloromethane via MP2 and/or M062X optimizations), are listed in Table S4 in the Supporting Information. The data in Tables 3 and S4 indicate that electron densities at the BCPs increase exponentially with a decrease in interatomic $\mathrm{Br} \cdots \mathrm{Y}$ separations (similar to the changes of magnitudes of $\Delta E$ values). For the series of complexes with the same nucleophile, all points follow the same exponential trend line regardless of the computational method, charges of species, and medium (Figure 3 ).

The linear plots of $\ln (\rho)$ versus $d_{\mathrm{Br} \ldots \mathrm{Y}}$ for each series (with $R^{2}$ $>0.99$ ) are characterized by the same slope of $-2.00 \pm 0.02$ (Figure S2 in the Supporting Information). The intersections of the linear plots increase from 1.90 to 2.20 and to $2.33 \AA$ for complexes of $\mathrm{RBr}$ with $\mathrm{DABCO}$, chloride, and bromide, respectively, following the corresponding $\mathrm{Br}-\mathrm{N}, \mathrm{Br}-\mathrm{Cl}$, and $\mathrm{Br}-\mathrm{Br}$ covalent bond lengths of 1.94, 2.17, and $2.30 \AA$ in $\mathrm{DABCO}-\mathrm{Br}^{+}, \mathrm{ClBr}$, and $\mathrm{Br}_{2}$. It is also noticeable that comparable values of $\rho(\mathbf{r})$ are observed at the shortest separations in associations with $\mathrm{DABCO}$ (blue), intermediate
Table 3. Electron Density, $\rho(r)$, the Laplacian of Density, $\nabla^{2} \rho(\mathrm{r})$, Kinetic, $G(\mathrm{r})$, and Potential, $V(\mathrm{r})$, Energy Densities, and Energy Density, $H(r)$, (All in Atomic Units) at the $\mathrm{BCPs}$ between $\mathrm{Br}$ and $\mathrm{N}$ Atoms in Complexes of $\mathrm{RBr}$ with $\mathrm{DABCO}^{a}$

\begin{tabular}{|c|c|c|c|c|c|}
\hline $\mathrm{RBr}$ & $10^{2} \rho(\mathbf{r})$ & $10^{2} \nabla^{2} \rho(\mathbf{r})$ & $10^{2} G(\mathbf{r})$ & $10^{2} V(\mathbf{r})$ & $10^{2} H(\mathbf{r})$ \\
\hline $\mathrm{CH}_{3} \mathrm{Br}$ & 1.717 & 5.083 & 1.195 & -1.119 & 0.076 \\
\hline $\mathrm{CH}_{2} \mathrm{BrF}$ & 1.828 & 5.342 & 1.264 & -1.193 & 0.071 \\
\hline $\mathrm{CH}_{2} \mathrm{Br}_{2}$ & 2.159 & 6.257 & 1.509 & -1.454 & 0.055 \\
\hline $\mathrm{BrCCH}$ & 2.343 & 6.909 & 1.674 & -1.621 & 0.053 \\
\hline $\mathrm{C}_{6} \mathrm{Br}_{2} \mathrm{~F}_{4}$ & 2.634 & 7.496 & 1.856 & -1.839 & 0.017 \\
\hline $\mathrm{C}_{2} \mathrm{Br}_{2} \mathrm{~F}_{4}$ & 2.643 & 7.368 & 1.832 & -1.822 & 0.010 \\
\hline $\mathrm{CHBr}_{3}$ & 2.800 & 7.782 & 1.955 & -1.964 & -0.093 \\
\hline $\mathrm{CBr}_{3} \mathrm{CONH}_{2}$ & 3.327 & 8.854 & 2.307 & -2.400 & -0.093 \\
\hline $\mathrm{CBr}_{3} \mathrm{~F}$ & 3.190 & 8.587 & 2.215 & -2.283 & -0.068 \\
\hline $\mathrm{CBr}_{3} \mathrm{COCBr}_{3}$ & 3.650 & 9.532 & 2.539 & -2.695 & -0.156 \\
\hline $\mathrm{CBrCl}_{3}$ & 3.545 & 9.327 & 2.466 & -2.600 & -0.134 \\
\hline $\mathrm{CBr}_{4}$ & 3.729 & 9.654 & 2.587 & -2.761 & -0.174 \\
\hline $\mathrm{CBr}_{3} \mathrm{CN}$ & 4.040 & 10.112 & 2.776 & -3.025 & -0.249 \\
\hline $\mathrm{CBr}_{3} \mathrm{NO}_{2}$ & 3.968 & 10.008 & 2.731 & -2.960 & -0.229 \\
\hline $\mathrm{CBr}\left(\mathrm{NO}_{2}\right)_{3}$ & 4.277 & 10.503 & 2.931 & -3.236 & -0.305 \\
\hline BrSIM & 5.758 & 12.417 & 3.961 & -4.819 & -0.857 \\
\hline BrPIM & 5.808 & 12.441 & 3.991 & -4.873 & -0.881 \\
\hline $\mathrm{Br}_{2}$ & 6.601 & 12.635 & 4.370 & -5.582 & -1.212 \\
\hline BrSAC & 7.065 & 12.830 & 4.718 & -6.229 & -1.511 \\
\hline $\mathrm{BrCl}$ & 6.914 & 12.842 & 4.594 & -5.977 & -1.383 \\
\hline $\mathrm{BrF}$ & 8.040 & 13.359 & 5.449 & -7.557 & -2.109 \\
\hline DABCO-Br ${ }^{+}$ & 9.091 & 10.782 & 5.466 & -8.236 & -2.770 \\
\hline NBr-pyrazine ${ }^{+}$ & 10.469 & 9.479 & 6.252 & -10.133 & -3.882 \\
\hline $\mathrm{F}_{5} \mathrm{Pyr}-\mathrm{Br}^{+}$ & 12.683 & 6.515 & 7.612 & -13.595 & -5.983 \\
\hline $\mathrm{Br}^{+}$ & 13.858 & 3.883 & 8.112 & -15.253 & -7.141 \\
\hline
\end{tabular}

${ }^{a}$ For complexes obtained via MP2/6-311++G $(\mathrm{d}, \mathrm{p})$ calculations in the gas phase. The values obtained from M062X/6-311+G(d,p) calculations as well as the corresponding characteristics of the complexes with $\mathrm{Cl}^{-}$and $\mathrm{Br}^{-}$anions are listed in Table S4 in the Supporting Information.

in complexes with $\mathrm{Cl}^{-}$(green), and at the longest separations in associations with $\mathrm{Br}^{-}$(red). This trend reflects the variations of the radial dependencies of the electron density in nitrogen, chlorine, and bromine (and sizes of these atoms). Since isodensity envelopes of various molecules (e.g., at 0.001 a.u. values) could be modeled reasonably well using van der Waals radii, ${ }^{41}$ the dependence of the $\mathrm{BCP}$ densities was also plotted versus normalized separations, $R_{\mathrm{BrY}}$, defined as

$$
R_{\mathrm{BrY}}=d_{\mathrm{Br} \cdots \mathrm{Y}} /\left(r_{\mathrm{Br}}+r_{\mathrm{Y}}\right)
$$

where $d_{\mathrm{Br} \cdots \mathrm{Y}}$ is the distance between bromine and $\mathrm{Cl}^{-}, \mathrm{Br}^{-}$, or the nitrogen atom of $\mathrm{DABCO}$ and $r_{\mathrm{Br}}$ and $r_{\mathrm{Y}}$ are the van der Waals radii of the corresponding atoms. ${ }^{42}$ In this case, all points follow the same line (with an $R^{2}$ of 0.997 ) regardless of the nucleophile, computational method, or medium (see the
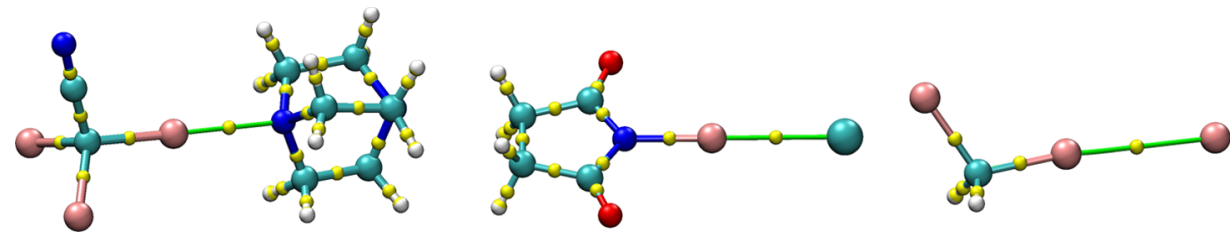

Figure 2. $\mathrm{XB}$ bond paths (green lines) and (3,-1) BCPs (small yellow spheres) in XB complexes $\mathrm{CBr}_{3} \mathrm{CN} \cdot \mathrm{DABCO}\left(\right.$ left), $\mathrm{BrSIM} \cdot \mathrm{Cl}^{-}(\mathrm{center})$, and $\mathrm{CBr}_{2} \mathrm{H}_{2} \cdot \mathrm{Br}^{-}$(right). 


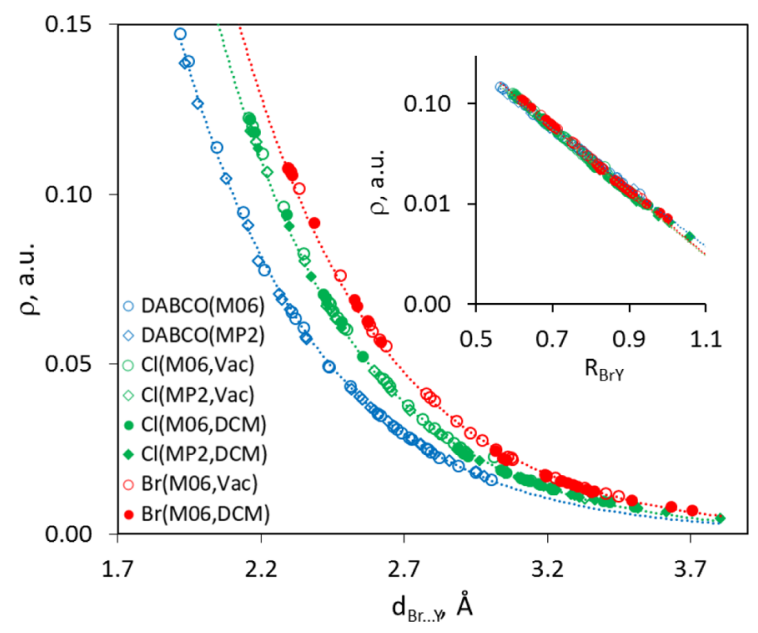

Figure 3. Dependencies of electron densities at BCPs on $\mathrm{Br} \cdots \mathrm{Y}$ separations for the $\mathrm{XB}$ complexes between $\mathrm{RBr}$ electrophiles and DABCO (blue), $\mathrm{Cl}^{-}$(green), and $\mathrm{Br}^{-}$(red). Rhombuses and circles show values for the MP2- and M062X-optimized complexes, respectively, and filled and open symbols show values for complexes optimized in dichloromethane or the gas phase, respectively.

inset in Figure 3). This unified trend line suggests that the normalized $\mathrm{XB}$ length is apparently a principal parameter which determines electron densities at BCPs at the $\mathrm{Br} \cdots \mathrm{Y} \mathrm{XB}$ paths.

It should be mentioned that the complexes with interatomic $\mathrm{Br} \cdots \mathrm{Y}$ distances close to the van der Waals separations are characterized by the values of $\rho(\mathbf{r})$ of the order of 0.01 a.u., which are common for the CS interactions such as ionic bonds and weak supramolecular bonds. ${ }^{17}$ At the other limit, in the complexes with the $\mathrm{Br} \cdots \mathrm{Y}$ distances $30-40 \%$ shorter than the van der Waals separation, the values of $\rho$ are about 1 order of magnitude larger at approximately 0.1 a.u. Such values of electron density at BCPs are typical for SS (covalent) interactions. $^{17}$ Each series of complexes with a certain nucleophile show continuums of the bond distance and density dependencies without any break or gap, that is, a gradual decrease in the interatomic distances is accompanied by a smooth increase in densities. Such a continuity suggests a direct relation between the covalent bondings taking place at the limit of the short separations and interactions at the $\mathrm{Br} \cdots \mathrm{Y}$ distances close to van der Waals separations. To examine transitions and boundaries between these limiting cases, we turned to the analysis of the Laplacians of electron density,

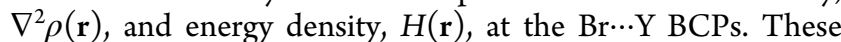
two characteristics were most commonly used for the identification of the covalent, noncovalent, or intermediate bonding in earlier studies. ${ }^{18-20}$

The Laplacians of the electron densities represent the sum of the three eigenvalues of the Hessian. They provide information about either the charge concentration $\left[\nabla^{2} \rho(\mathbf{r})<0\right]$ or the charge depletion $\left[\nabla^{2} \rho(\mathbf{r})>0\right]$ of the electron distribution at BCPs. The behaviors of $\nabla^{2} \rho(\mathbf{r})$ values are usually different in covalent and noncovalent regions. ${ }^{18}$ The dependencies of the Laplacians of electron density, $\nabla^{2} \rho(\mathbf{r})$, on the interatomic Br $\cdots$ $\mathrm{Y}$ separations in $\mathrm{XB}$ complexes under study are shown in Figure 4.

As was observed with the densities, $\rho(\mathbf{r})$, the Laplacian values for the complexes of $\mathrm{RBr}$ electrophiles with each nucleophile followed essentially the same dependencies on the interatomic distances regardless of the calculation methods,

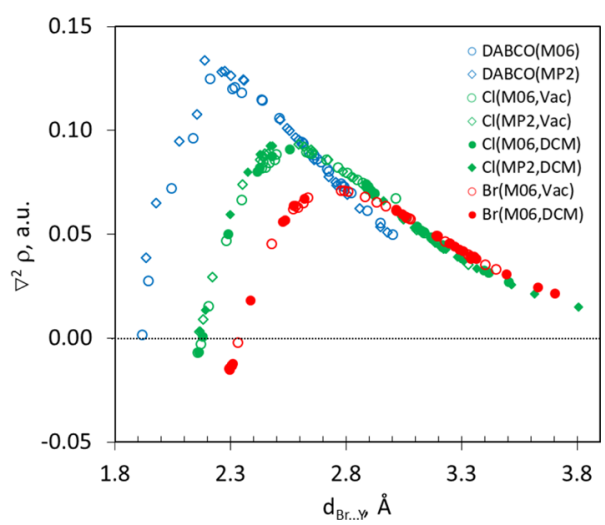

Figure 4. Dependencies of the Laplacian $\nabla^{2} \rho$ values at BCPs on $\mathrm{Br} \cdots$ $\mathrm{Y}$ separations for $\mathrm{XB}$ complexes between $\mathrm{RBr}$ electrophiles and $\mathrm{DABCO}$ (blue), $\mathrm{Cl}^{-}$(green), and $\mathrm{Br}^{-}$(red).

charges, or media. Also, the comparable values of $\nabla^{2} \rho(\mathbf{r})$ are observed at the shortest $d_{\mathrm{Br} \cdots \mathrm{Y}}$ distances for the complexes with $\mathrm{DABCO}$ and at the largest separations in complexes with bromide, following the trend of the increase of van der Waals radii of interacting atoms.

Overall, the shapes of the dependencies of $\nabla^{2} \rho(\mathbf{r})$ on interatomic $\mathrm{Br} \cdots \mathrm{Y}$ separations are similar to those observed with the HB complexes. ${ }^{20}$ At large separations, the values of $\nabla^{2} \rho(\mathbf{r})$ are positive and relatively small. As the $d_{\mathrm{Br} \cdots \mathrm{Y}}$ distance decreases, the $\nabla^{2} \rho(\mathbf{r})$ values increase (the greater charge depletion is observed). The maxima of the $\nabla^{2} \rho$ values in each series are observed at the $\mathrm{Br} \cdots \mathrm{Y}$ distances about $30 \%$ shorter than the van der Waals separations. A further decrease in $d_{\mathrm{Br} \cdots \mathrm{Y}}$ is accompanied by the decrease in the Laplacian values. At the shortest $d_{\mathrm{Br} \cdots \mathrm{Y}}$ distances corresponding to the covalent bonds, the Laplacian values in the associations under study are very small and either positive (for complexes with $\mathrm{DABCO}$ ) or negative (in complexes with $\mathrm{Cl}^{-}$or $\mathrm{Br}^{-}$). This behavior differs from the tendencies observed in the studies of $\mathrm{HB}$ complexes (which showed negative $\nabla^{2} \rho$ values, with the magnitudes increasing exponentially with the decreasing the bond length in the covalent-bond region ${ }^{18}$ ) However, similar positive or small negative Laplacian values were found earlier for the other covalent bonds formed by the highly polar atoms, which suggests that the Laplacian values of BCPs are not always a reliable indicator to allow an accurate covalent or noncovalent bond type assignment. ${ }^{43}$ Therefore, the local energy density $H(\mathbf{r})$ was proposed to complete the identification of the interatomic interactions. ${ }^{43}$ Positive and negative values of $H(\mathbf{r})$ have been used as an alternative way of defining ionic and covalent bonds because this quantity avoids the problems observed for $\nabla^{2} \rho(\mathbf{r})$ with some covalent bonds. For example, bonds involving electronegative atoms, such as $\mathrm{F}_{2}, \mathrm{CO}, \mathrm{H}_{2} \mathrm{CO}$, and $\mathrm{HCN}$, show positive values of $\nabla^{2} \rho(\mathbf{r})$, whereas the corresponding values of $H(\mathbf{r})$ are negative for these bonds, which is similar to the other covalent bonds. ${ }^{43,44}$

The variations of the $H(\mathbf{r})$ values with interatomic distances are determined by the changes in magnitudes of their two components, that is, kinetic energy and potential energy densities, $G(\mathbf{r})$ and $V(\mathbf{r})$, respectively. ${ }^{17}$ The variations of these characteristics with the interatomic separations in the $\mathrm{XB}$ complexes under study are shown in Figure 5.

In the series of $\mathrm{XB}$ complexes of different $\mathrm{RBr}$ electrophiles with the same nucleophile, the values of the kinetic energy density $G(\mathbf{r})$ increase exponentially with a decrease in the 


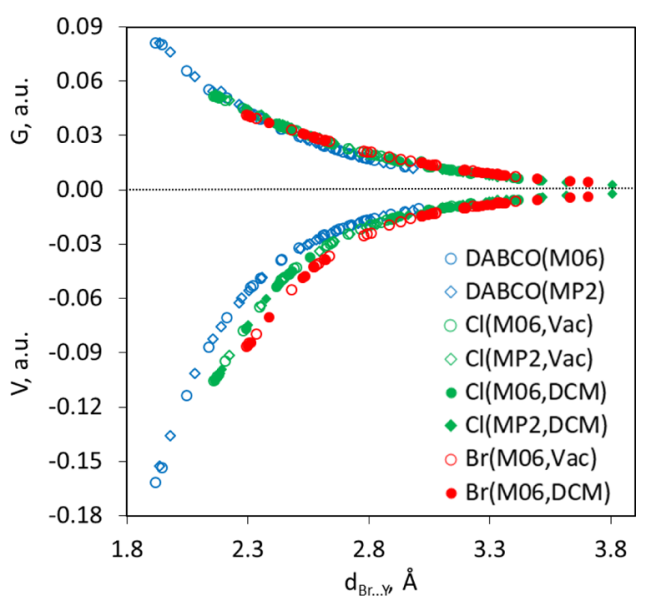

Figure 5. Dependencies of the kinetic $(G)$ and potential $(V)$ energy densities at $\mathrm{BCPs}$ on the $\mathrm{Br} \cdots \mathrm{Y}$ separations for $\mathrm{XB}$ complexes between $\mathrm{RBr}$ electrophiles and DABCO (blue), $\mathrm{Cl}^{-}$(green), and $\mathrm{Br}^{-}$(red).

interatomic separations $d_{\mathrm{Br} . . \mathrm{Y}}$. Similar to the values of $\rho(\mathbf{r})$ and $\nabla^{2} \rho(\mathbf{r})$, the variations of $G(\mathbf{r})$ in each series are essentially independent of the method, charges of reactants, or medium. They are described by the trend lines of $y=2.83 \times$ $\exp (-1.82 x), y=2.25 \times \exp (-1.70 x)$, and $y=1.59 \times$ $\exp (-1.56 x)$ for complexes with $\mathrm{DABCO}, \mathrm{Cl}^{-}$, and $\mathrm{Br}^{-}$, respectively (all with $R^{2}>0.995$ ). Noticeably, both the preexponential factors and the exponents decrease with the increase in the van der Waals radii of the nucleophiles (i.e., the dependence describing complexes with $\mathrm{DABCO}$ is the steepest function). The potential energy densities, $V(\mathbf{r})$, are negative, and their magnitudes also increase exponentially with the decrease in the interatomic separations. They are characterized by trend lines of $y=-18.72 \times \exp (-2.52 x), y=-18.55 \times$ $\exp (-2.42 x)$, and $y=-17.78 \times \exp (-2.34 x)$ for complexes with $\mathrm{DABCO}$, chloride, and bromide, respectively (all with $R^{2}$ $=0.998)$. The variations of the pre-exponential factors and exponents with the nucleophile follow the same trend as that observed for $G(\mathbf{r})$. Most notably, the magnitudes of the preexponential factors and exponents describing the dependencies of the potential energy densities on the $d_{\mathrm{Br} \cdots \mathrm{Y}}$ distance are larger than the corresponding values for $G(\mathbf{r})$. This means that variations of the values of $V(\mathbf{r})$ with interatomic distances are steeper. Therefore, the magnitudes of the kinetic energies are higher at larger separations, and the values of $H(\mathbf{r})$ are positive in this region due to the excess of kinetic energy over potential energy (Figure 6). At the limit of short separations, the potential energy dominate, and the values of $H(\mathbf{r})$ are negative and become more negative as atoms approach each other. The $H(\mathbf{r})$ values determined for the series of $\mathrm{XB}$ complexes of different $\mathrm{RBr}$ electrophiles with a certain nucleophile using different methods or media followed essentially the same line (Figure 6). Furthermore, the comparable values of $H(\mathbf{r})$ are observed at the shortest separations for complexes with $\mathrm{DABCO}$ and at the longest separations for complexes with bromide. The dependencies of $H(\mathbf{r})$ on the normalized interatomic separation $\mathrm{R}_{\mathrm{BrX}}$ for the $\mathrm{XB}$ complexes of $\mathrm{RBr}$ molecules with all three nucleophiles are very close (inset in Figure 6). Notably, the transitions between positive and negative values of $H(\mathbf{r})$ occur in each series at $R \sim 0.78$, that is, at the separation, which is about $22 \%$ shorter than the sum of the van der Waals radii of the interacting atoms (inset in Figure 6).

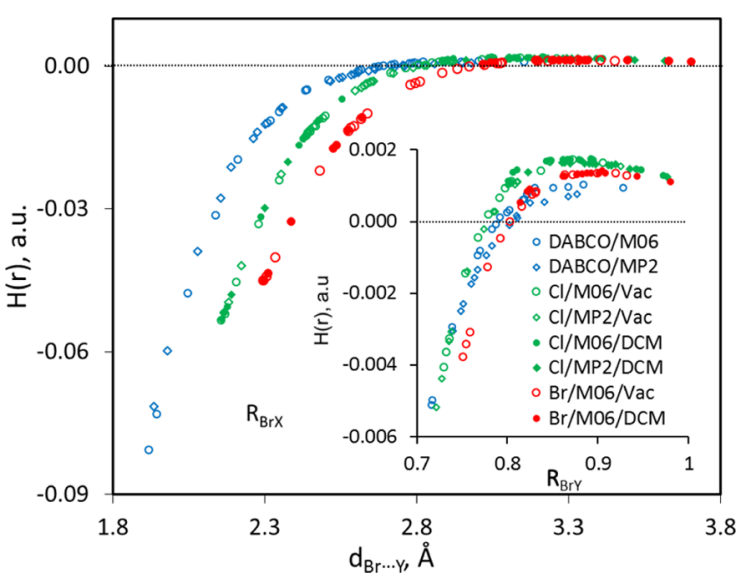

Figure 6. Dependencies of the energy densities $H(\mathbf{r})$ at BCPs on the $\mathrm{Br}-\mathrm{Y}$ separations for $\mathrm{XB}$ complexes between $\mathrm{RBr}$ electrophiles and $\mathrm{DABCO}$ (blue), $\mathrm{Cl}^{-}$(green), and $\mathrm{Br}^{-}$(red). Inset: Enlarged section of the graph showing transition between positive and negative values of $H(\mathbf{r})$, with the latter plotted vs the normalized interatomic separations.

Combinations of characteristic features of $\nabla^{2} \rho(\mathbf{r})$ and $H(\mathbf{r})$ have been used previously to divide the whole range of interatomic distances in the $\mathrm{HB}$ complexes into three regions: region I $\left[\nabla^{2} \rho(\mathbf{r})>0\right.$ and $\left.H(\mathbf{r})>0\right]$, region II $\left[\nabla^{2} \rho(\mathbf{r})>0\right.$ and $H(\mathbf{r})<0]$, and region III $\left[\nabla^{2} \rho(\mathbf{r})<0\right.$ and $\left.H(\mathbf{r})<0\right] .{ }^{20}$ Region I represented weak hydrogen bonding (pure CS interactions). Region II was associated with CS interactions with some covalent character (HB energies typically between 50 and 100 $\mathrm{kJ} / \mathrm{mol}$ ). Region III was related to SS interactions (strong hydrogen and covalent bonds). In the halogen-bonded complexes under study, the variations of the $H(\mathbf{r})$ values with interatomic separations are similar to that observed in $\mathrm{HB}$ systems. Nevertheless, the $\nabla^{2} \rho(\mathbf{r})$ values are close to zero (either positive or negative), even in the $\mathrm{XB}$ associations with the $d_{\mathrm{Br} \cdots \mathrm{Y}}$ distances close to the typical covalent $\mathrm{Br}-\mathrm{Y}$ bonds and $\mathrm{XB}$ energies of more than $100 \mathrm{~kJ} / \mathrm{mol}$ (see Table S3 in the Supporting Information). Thus, the classification based on both $\nabla^{2} \rho(\mathbf{r})<0$ and $H(\mathbf{r})<0$ values is apparently not wellsuited for the $\mathrm{XB}$ associations [the complexes showing $\nabla^{2} \rho(\mathbf{r})$ $<0$ and $H(\mathbf{r})<0$ (region III) are not present]. It should be also mentioned that the three regions were also defined by the magnitudes of the $|V(\mathbf{r})| / G(\mathbf{r})$ ratio. Specifically, the values of $\mid$ $V(\mathbf{r}) \mid / G(\mathbf{r})<1$ (region I), $1<|V(\mathbf{r})| / G(\mathbf{r})<2$ (region II), and $|V(\mathbf{r})| / G(\mathbf{r})>2$ (region III) were used for the identification and quantification of the CS and SS interactions in the studies of the metal-oxide-bonded interactions and metal-metal interactions ${ }^{45,46}$ This approach is fundamentally equivalent to that based on the combinations of $\nabla^{2} \rho(\mathbf{r})$ and $H(\mathbf{r})$ values [taking into account the local form of the virial theorem $2 G(\mathbf{r})$ $+V(\mathbf{r})=1 / 4 \nabla^{2} \rho(\mathbf{r})$ and the definition of $H(\mathbf{r})=G(\mathbf{r})+$ $\left.V(\mathbf{r})^{17,18}\right]$ : Thus, in the systems under study, even the essentially covalent $\mathrm{Br} \cdots \mathrm{X}$ bonds are characterized by the I $V(\mathbf{r}) \mid / G(\mathbf{r})$ ratios close to 2 .

To further explore transitions from weak to strong $R_{\mathrm{Br} \cdots \mathrm{Y}}$ complexes, we examined the effects of $R_{\mathrm{Br} \cdots \mathrm{Y}}$ interactions on the characteristics of the $\mathrm{R}-\mathrm{Br}$ bonds in the $\mathrm{XB}$ donors. Indeed, QTAIM analysis of the electron density distribution revealed that $\mathrm{XB}$ formation is accompanied by the transfer of a substantial part of the electron density that was originally located on the nucleophile to the $\mathrm{RBr}$ electrophile moiety. Dependencies of the amounts of charge transfer on the $\mathrm{Br} \cdots \mathrm{Y}$ 
distances for the series of complexes of various electrophiles are illustrated in Figure 7.

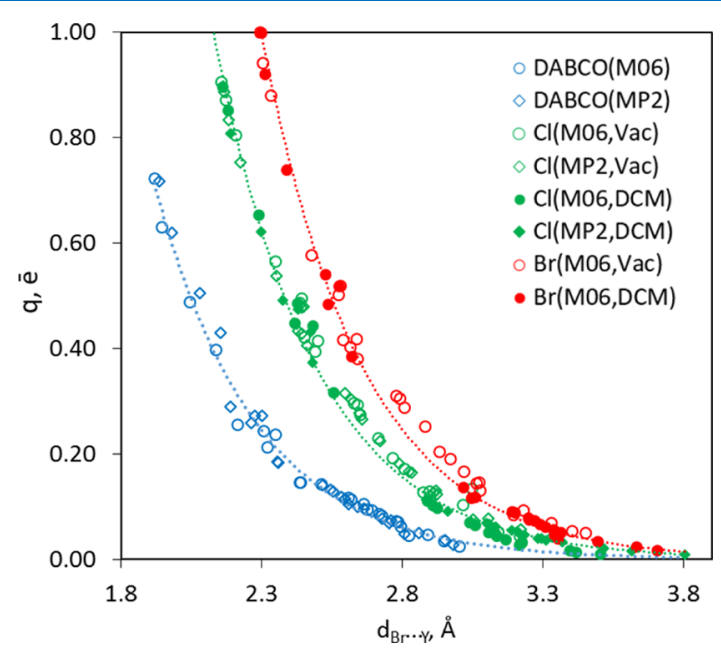

Figure 7. Dependencies of the amount of the charge transfer in $\mathrm{XB}$ complexes between $\mathrm{RBr}$ electrophiles and $\mathrm{DABCO}$ (blue), $\mathrm{Cl}^{-}$ (green), and $\mathrm{Br}^{-}$(red) on the $\mathrm{Br} \cdots \mathrm{Y}$ separations. Dashed lines show exponential trend lines.

A glance at Figure 7 reveals that the amount of charge transfer in the series of complexes of different $\mathrm{RBr}$ electrophiles with the same nucleophile is increasing exponentially with the decrease in the interatomic $\mathrm{Br} \cdots \mathrm{Y}$ separations. Also, the values calculated using different methods (MP2 or DFT) and/or in various media (dichloromethane or the gas phase) follow essentially the same trend lines for all series with all three nucleophiles. These exponential dependencies are very similar to the variations of electron density values at BCPs in Figure 3 and interaction energies in Figure 1. These similarities suggest that charge transfer plays a substantial role in the $\mathrm{XB}$ associations. Importantly, the NBO analysis indicated that electron density is transferred mostly to the antibonding $\sigma^{*}$ orbital of the $\mathrm{R}-\mathrm{Br}$ molecules, ${ }^{13,14}$ thereby leading to substantial changes in the $\mathrm{R}-\mathrm{Br}$ bonding. These changes are reflected in the lengthening of the bond between $\mathrm{Br}$ and residue $\mathrm{R}$. Since $\mathrm{Br}$ in the $\mathrm{R}-\mathrm{Br}$ molecule is bonded to different atoms $(\mathrm{C}, \mathrm{N}, \mathrm{Br}, \mathrm{Cl}$, and $\mathrm{F})$, such lengthening can be quantified uniformly using the $d_{\mathrm{RBr}}^{\mathrm{C}} / d_{\mathrm{RBr}}^{\text {ind }}$ ratios of the $\mathrm{R}-\mathrm{Br}$ bond length in the complex $\left(d_{\mathrm{RBr}}^{\mathrm{C}}\right)$ to that in the individual $\mathrm{RBr}$ molecule $\left(d_{\mathrm{RBr}}^{\mathrm{ind}}\right)$. The variations of these ratios with the normalized $\mathrm{Br} \cdots \mathrm{Y}$ separations are illustrated in Figure 8.

A comparison of Figures 7 and 8 shows that while the amount of charge transfer is increasing exponentially over the whole range of $\mathrm{Br} \cdots \mathrm{Y}$ distances, the $d_{\mathrm{RBr}}^{\text {ind }} / d_{\mathrm{RBr}}^{\text {ind }}$ ratios remain close to 1 in the range with $R_{\mathrm{BrY}}>0.8$. This means that the $\mathrm{R}-$ $\mathrm{Br}$ bond lengths remain essentially unaffected when $\mathrm{Br} \cdots \mathrm{Y}$ separations are within $20 \%$ of the sum of the van der Waals radii. At $R_{\mathrm{BrY}}$ values less than about 0.78 , the ratios $d_{\mathrm{RBr}}^{\text {ind }} / d_{\mathrm{RBr}}^{\text {ind }}$ start to increase steadily with the decrease in the $\mathrm{XB}$ length. Apparently, a normalized separation $R_{\mathrm{BrY}} \sim 0.78$ represents a point at which $H(\mathbf{r})$ values transition from positive to negative values (Figure 6), and XB starts to substantially impact the RBr molecule.

Since the bond strength between two species is highly correlated with the electron density at the corresponding BCPs, we evaluated the changes in the $\rho(\mathbf{r})$ values at BCPs on the $\mathrm{R}-\mathrm{Br}$ bond path in the $\mathrm{XB}$ donor occurring upon $\mathrm{XB}$ with

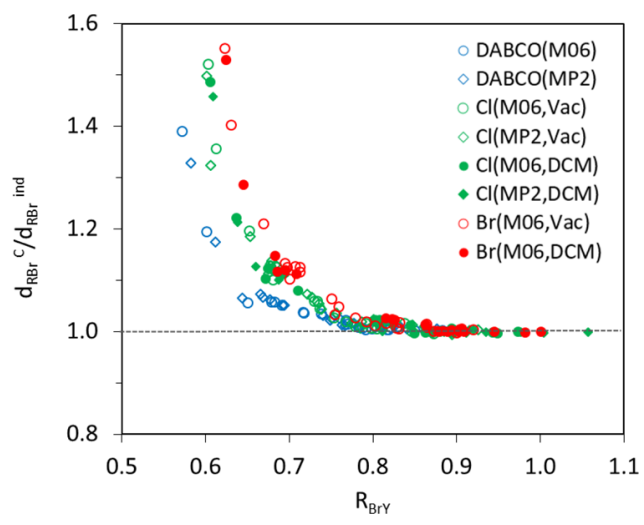

Figure 8. Dependencies of the amount of ratios of $\mathrm{R}-\mathrm{Br}$ bond lengths in the $\mathrm{XB}$ complexes between $\mathrm{RBr}$ electrophiles and $\mathrm{DABCO}$ (blue), $\mathrm{Cl}^{-}$(green), and $\mathrm{Br}^{-}$(red) to that in the individual $\mathrm{R}-\mathrm{Br}$ molecules on the normalized $\mathrm{Br} \cdots \mathrm{Y}$ separations.

$\mathrm{Y}$ nucleophiles. Such changes can be quantified using ratios $\rho_{\mathrm{RBr}}(\mathbf{r}) / \rho_{\mathrm{RBr}}(\mathbf{r})^{\text {ind }}$, where $\rho_{\mathrm{RBr}}(\mathbf{r})$ is the electron density value at $\mathrm{BCPs}$ along $\mathrm{R}-\mathrm{Br}$ bond paths in the halogen-bonded $\mathrm{RBr}$ electrophile and $\rho_{\mathrm{RBr}}(\mathbf{r})^{\text {ind }}$ is the corresponding electron density values in the individual $\mathrm{XB}$ donor. The dependencies of these ratios on $\mathrm{Br} \cdots \mathrm{Y}$ separations are illustrated in Figure 9.

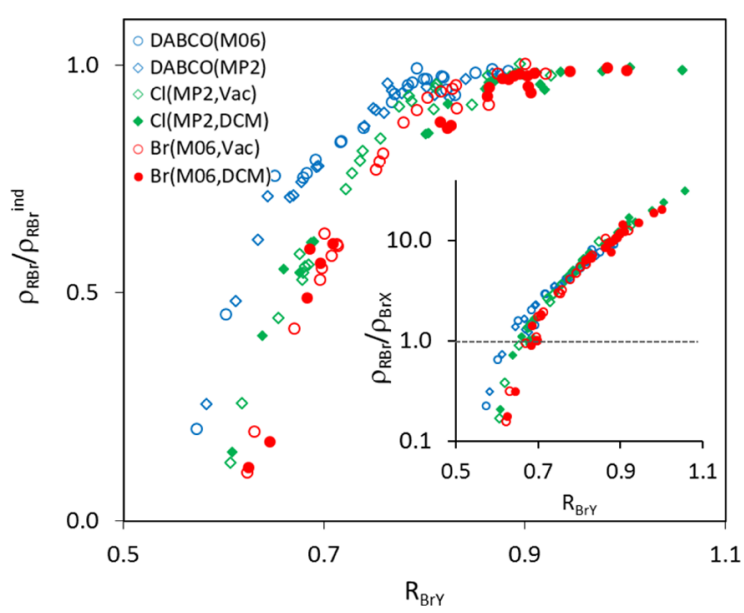

Figure 9. Dependencies of $\rho_{\mathrm{RBr}}(\mathbf{r}) / \rho_{\mathrm{RBr}}(\mathbf{r})^{\text {ind }}$ ratios on the normalized $\mathrm{Br} \cdots \mathrm{Y}$ separations, where $\rho_{\mathrm{RBr}}(\mathbf{r})$ is an electron density at a $\mathrm{BCP}$ along the $\mathrm{R}-\mathrm{Br}$ bond path in an $\mathrm{XB}$ complex with $\mathrm{DABCO}$ (blue), $\mathrm{Cl}^{-}$ (green), and $\mathrm{Br}^{-}$(red) and $\rho_{\mathrm{Br}}(\mathbf{r})^{\text {ind }}$ is the corresponding electron density value in the individual $\mathrm{RBr}$ electrophile. Inset: dependence of $\rho_{\mathrm{RBr}}(\mathbf{r}) / \rho_{\mathrm{BrY}}(\mathbf{r})$ ratios [where $\rho_{\mathrm{BrY}}(\mathbf{r})$ is the electron density at the $\mathrm{BCP}$ on the $\mathrm{Br} \cdots \mathrm{Y}$ bond path] on the normalized $\mathrm{Br} \cdots \mathrm{Y}$ separations.

The data in Figure 9 show that changes in electron densities at the $\mathrm{BCPs}$ on the $\mathrm{Br}-\mathrm{R}$ bond followed trends similar to that of the $\mathrm{Br}-\mathrm{R}$ bond length. In particular, at the limit of large $\mathrm{Br} \cdots \mathrm{Y}$ separations where $R_{\mathrm{BrY}}>0.80$, the $\rho_{\mathrm{RBr}}(\mathbf{r}) / \rho_{\mathrm{RBr}}(\mathbf{r})^{\text {ind }}$ ratios remain close to 1 . This confirms that in this range, the formation of the $\mathrm{XB}$ between $\mathrm{R}-\mathrm{Br}$ and $\mathrm{Y}$ does not substantially affect the $\mathrm{R}-\mathrm{Br}$ bond. At $R_{\mathrm{BrY}}$ values lower than about $0.75-0.80$, the $\rho_{\mathrm{RBr}}(\mathbf{r}) / \rho_{\mathrm{RBr}}(\mathbf{r})^{\text {ind }}$ ratios start to decrease with the decrease in the $\mathrm{Br} \cdots \mathrm{Y}$ distances. Noticeably, the transition from the $R_{\mathrm{Br} Y}$-independent ratios $\rho_{\mathrm{RBr}}(\mathbf{r}) \rho_{\mathrm{RBr}}(\mathbf{r})^{\text {ind }} \sim$ 1 to the steep decrease in these ratios is observed at about the same $R_{\mathrm{BrY}}$ value as the transition between positive and negative $H(\mathbf{r})$ values shown in Figure 6. Apparently, below the $R_{\mathrm{BrY}}$ 
value of about 0.78 , the molecular orbital (covalent) interactions between $\mathrm{RBr}$ and $\mathrm{Y}$ play a substantial role in $\mathrm{XB}$, and the latter substantially affects the bond between $\mathrm{Br}$ and $\mathrm{R}$ residues. To clarify these effects, we compared electron densities $\rho_{\mathrm{RBr}}(\mathbf{r})$ at $\mathrm{BCPs}$ on the $\mathrm{R}-\mathrm{Br}$ bond path in the $\mathrm{XB}$ donor with the $\rho_{\mathrm{BrY}}(\mathbf{r})$ values on the $\mathrm{Br} \cdots \mathrm{Y}$ path. The ratios $\rho_{\mathrm{RBr}}(\mathbf{r}) / \rho_{\mathrm{BrY}}(\mathbf{r})$ of these values are illustrated in the inset in Figure 9. At large $\mathrm{Br} \cdots \mathrm{Y}$ separations, the electron density at the $\mathrm{R}-\mathrm{Br}$ BCPs (representing covalent bonds) is much larger than the densities at the BCPs on the $\mathrm{Br} \cdots \mathrm{Y}$ bond path, representing supramolecular bonds. As is shown in Figure 3, the decrease in the $\mathrm{Br} \cdots \mathrm{Y}$ separations is accompanied by the increase in the electron densities $\rho_{\mathrm{BrY}}(\mathbf{r})$ at the BCPs along the $\mathrm{Br} \cdots \mathrm{Y}$ bond path. Simultaneously, the electron density $\rho_{\mathrm{RBr}}(\mathbf{r})$ at $\mathrm{R}-\mathrm{Br}$ BCPs decreases. These two trends result in the steep decrease in the $\rho_{\mathrm{RBr}}(\mathbf{r}) / \rho_{\mathrm{BrY}}(\mathbf{r})$ ratios with the decrease in $R_{\mathrm{BrY}}$. Ultimately, when $R_{\mathrm{BrY}}$ values are less than about 0.66 , the $\rho_{\mathrm{RBr}}(\mathbf{r}) / \rho_{\mathrm{BrY}}(\mathbf{r})$ ratios are lower than 1 . This means that the electron density at the BCP at the $\mathrm{R}-\mathrm{Br}$ bond path is smaller than that at the $\mathrm{Br} \cdots \mathrm{Y}$ bond path. Since electron densities at $\mathrm{BCPs}$ are indicators of the corresponding bond strengths, this transition means that $\mathrm{Br} \cdots \mathrm{Y}$ bonds become stronger than $\mathrm{R}-\mathrm{Br}$ bonds.

A comparison of the values of the energy densities $H(\mathbf{r})$ at BCPs on $\mathrm{R}-\mathrm{Br}$ and $\mathrm{Br} \cdots \mathrm{Y}$ bond paths $\left[H(\mathbf{r})_{\mathrm{RBr}}\right.$ and $H(\mathbf{r})_{\mathrm{BrY}}$, respectively] reveals similar tendencies in the variations of the relative strength of these bonds. The dependencies of the difference $\Delta H(\mathbf{r})=H(\mathbf{r})_{\mathrm{RBr}}-H(\mathbf{r})_{\mathrm{BrY}}$ on the normalized $\mathrm{Br} \cdots$ $\mathrm{Y}$ separations are presented in Figure 10.

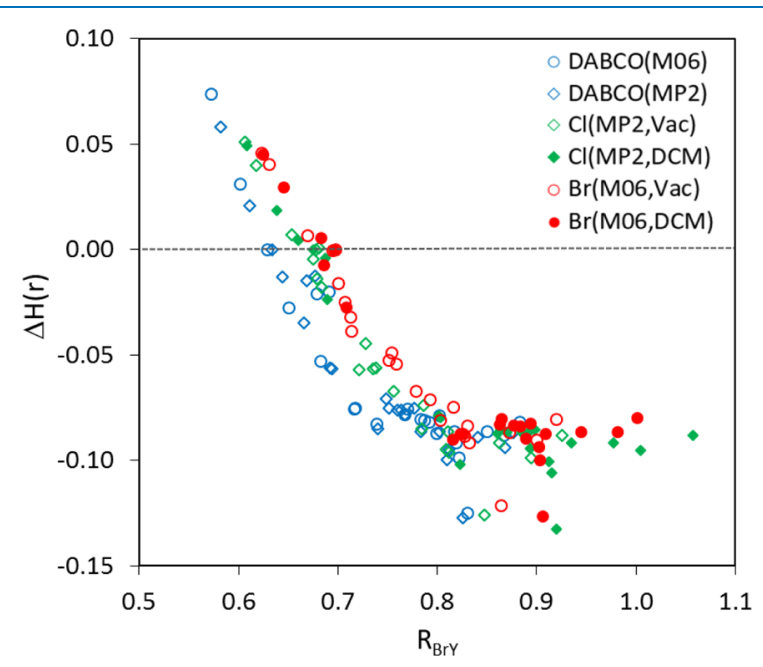

Figure 10. Dependencies of the difference $\Delta H(\mathbf{r})=H(\mathbf{r})_{\mathrm{RBr}}-$ $H(\mathbf{r})_{\mathrm{BrY}}$ on the normalized $\mathrm{Br} \cdots \mathrm{Y}$ separations $\left[H(\mathbf{r})_{\mathrm{RBr}}\right.$ and $H(\mathbf{r})_{\mathrm{BrY}}$ are energy densities at the $\mathrm{BCPs}$ along the $\mathrm{R}-\mathrm{Br}$ and $\mathrm{Br} \cdots \mathrm{Y}$ bond paths, respectively, in the $\mathrm{XB}$ complexes with $\mathrm{DABCO}$ (blue), $\mathrm{Cl}^{-}$(green), and $\mathrm{Br}^{-}$(red)].

Figure 10 shows that at an $R_{\mathrm{BrY}}$ larger than about $0.8, \Delta H(\mathbf{r})$ values are essentially independent of $R_{\mathrm{BrY}}$. Since $H(\mathbf{r})$ values are small and positive in this range, the scattering of points is determined by the differences of the $H(\mathbf{r})$ values in the individual $\mathrm{XB}$ donors [e.g., six points with most negative $\Delta H(\mathbf{r})$ values of about -0.13 are related to the larger magnitudes of negative energy densities at the BCPs between $\mathrm{Br}$ and the sp-hybridized carbon in bromoethyne]. At $R_{\mathrm{BrY}}$ values lower than 0.8 , values of $\Delta H(\mathbf{r})$ start to rise with the decrease in the $\mathrm{Br} \cdots \mathrm{Y}$ separations, and it becomes positive at an
$R_{\mathrm{BrY}}$ of about 0.67 . This means that when the $\mathrm{XB}$ bond lengths between $\mathrm{Br}$ and $\mathrm{Y}$ are about 33\% less than their van der Waals separations, the values of $H(\mathbf{r})_{\mathrm{BrY}}$ are more negative than the corresponding $H(\mathbf{r})_{\mathrm{RBr}}$ values, that is, the $\mathrm{Br} \cdots \mathrm{Y}$ bonds are stronger than the $\mathrm{R}-\mathrm{Br}$ bonds. In view of such a switch of a strength of these bonds, the $\mathrm{Br} \cdots \mathrm{Y}$ bonds can be identified as essentially covalent in this range, and $\mathrm{Y}-\mathrm{Br} \cdots \mathrm{R}$ interaction can be classified as supramolecular bonding.

\section{CONCLUSIONS}

Computational analysis of the series of halogen-bonded complexes revealed that the gradual decrease in the $\mathrm{Br} \cdots \mathrm{Y}$ separations in these associations is accompanied by the exponential increase in the binding energies and the charge transfer from the nucleophile to the $\mathrm{R}-\mathrm{Br}$ electrophile. It also led to an exponential increase in the electron densities and magnitudes of the kinetic and potential energy densities at the $\mathrm{BCPs}$ on the $\mathrm{Br} \cdots \mathrm{Y}$ bond path. Accordingly, the energy densities $H(\mathbf{r})$ at these BCPs transitioned from small positive values to negative values, and the Laplacians of the electron density increased to the maximum and then decreased with the shortening of the $\mathrm{XB} \mathrm{Br} \cdots \mathrm{Y}$ bond. Besides, the strengthening of the $\mathrm{Br} \cdots \mathrm{Y}$ bond led to the weakening of the adjacent bond between bromine and $\mathrm{R}$ in the $\mathrm{RBr}$ electrophile.

In the earlier studies, the $H(\mathbf{r})$ and $\nabla^{2} \rho(\mathbf{r})$ values (or closely related characteristics of electron and energy densities at BCPs) were used to identify three regions in the HB systems, that is, purely CS (noncovalent), SS (covalent), and intermediate bonding. ${ }^{17-22}$ It is thus interesting to note that these indices and other topological features of the BCPs at XBs as well as characteristics of the adjacent bonds in the $\mathrm{XB}$ donor followed the same or approximately the same trend lines when plotted against the normalized XB length, $R_{\mathrm{BrY}}$, regardless of the computational methods, media, nucleophiles, or charges on the XB donor and acceptors. Such a synchronous change of a variety of characteristics with $R_{\mathrm{BrY}}$ suggests that normalized separations can be used as a basic parameter in the identification of the intermolecular interaction type. In the systems with an $R_{\mathrm{BrY}}$ higher than about 0.78 , the energy densities $H(\mathbf{r})$ at BCPs are small and positive, and $\mathrm{XB}$ formation does not substantially affect the strength of the $\mathrm{R}-$ $\mathrm{Br}$ covalent bond, that is, the $\mathrm{XB}$ interactions are essentially noncovalent. In complexes with $R_{\mathrm{BrY}}$ values between about 0.67 and 0.78 , energy densities $H(\mathbf{r})$ at $(\mathrm{Br} \cdots \mathrm{Y})$ BCPs are negative, and the decrease in $\mathrm{Br} \cdots \mathrm{Y}$ separations is accompanied by the increase in the magnitude of $H(\mathbf{r})$. In this range, $\mathrm{XB}$ formation leads to the lengthening of the $\mathrm{R}-\mathrm{Br}$ bond length and decrease in the magnitude of the (negative) $H(\mathbf{r})$ values at the BCPs of the R-Br bonds. Such XB interactions can be classified as partially covalent. At an $R_{\mathrm{BrY}}$ less than about 0.67 , the electron densities at BCPs of the $\mathrm{Br} \cdots \mathrm{Y}$ bond are larger, and the energy densities are more negative than those at the $\mathrm{BCP}$ for the $\mathrm{R}-\mathrm{Br}$ bond. This indicates that the $\mathrm{Br} \cdots \mathrm{Y}$ bond becomes stronger than the $\mathrm{R}-\mathrm{Br}$ bond, that is, the $\mathrm{XB}$ can be regarded as essentially covalent. While the general applicability of the normalized interatomic separation for the classification of the other intermolecular interactions (e.g., in hydrogen or chalcogen bonding) remains to be examined, the data presented in the current work indicate that in the case of $\mathrm{XB}$ associations, the previously used criteria determining various segments of intermolecular bondings are directly related to this readily available characteristic. 
Finally, it should be mentioned that XB is most commonly related to the electrostatic attraction of nucleophiles to the areas of positive charge on the surfaces of the halogen atoms (enhanced by the polarization of the latter) as well as dispersion. ${ }^{47,48}$ Nevertheless, many experimental and computational studies pointed out the importance of charge transfer (weakly covalent) interactions in the formation of many halogen-bonded complexes. $9,14,49-54$ The continuum of all these characteristics in the series of fully optimized $\mathrm{XB}$ associations without any major gaps or abrupt changes suggests an inherent relationship between limiting (covalent and noncovalent) types of bonding and thus an onset of molecular-orbital interactions in the weaker bonds.

\section{ASSOCIATED CONTENT}

\section{SI Supporting Information}

The Supporting Information is available free of charge at https://pubs.acs.org/doi/10.1021/acsomega.1c03779.

$\mathrm{XB}$ distances in the solid-state associations and in the calculated complexes; correlation between XB lengths in the calculated and experimental structures; calculated binding energies in the XB complexes; electron densities, Laplacians of density, kinetic and potential energy densities, and energy densities at the $\mathrm{Br} \cdots \mathrm{Y}$ XB paths; dependencies of electron densities on the $\mathrm{XB}$ lengths; and calculated energies, ZPE, and BSSE values (PDF)

\section{AUTHOR INFORMATION}

\section{Corresponding Author}

Sergiy V. Rosokha - Department of Chemistry, Ball State University, Muncie, Indiana 47306, United States; ○ orcid.org/0000-0003-3172-8523; Email: svrosokha@ bsu.edu

\section{Authors}

Daniel K. Miller - Department of Chemistry, Ball State University, Muncie, Indiana 47306, United States

Cody Loy - Department of Chemistry, Ball State University, Muncie, Indiana 47306, United States; Present Address: Department of Medicinal Chemistry and Molecular Pharmacology, Purdue University, West Lafayette, Indiana, 47907, USA

Complete contact information is available at: https://pubs.acs.org/10.1021/acsomega.1c03779

\section{Author Contributions}

D.K.M.: QTAIM analysis of the XB complexes and writingreview and editing, C.L.: optimization and characterization of the $\mathrm{XB}$ complexes and writing-review and editing, S.V.R.: conceptualization, supervision, funding acquisition, data curation, visualization, and writing-original draft, review, and editing.

\section{Notes}

The authors declare no competing financial interest.

\section{ACKNOWLEDGMENTS}

We thank the National Science Foundation (grant CHE2003603) for financial support of this work. Calculations were done on Ball State University's beowulf cluster, which is supported by The National Science Foundation (MRI1726017) and Ball State University.

\section{REFERENCES}

(1) Cavallo, G.; Metrangolo, P.; Milani, R.; Pilati, T.; Priimagi, A.; Resnati, G.; Terraneo, G. The halogen bond. Chem. Rev. 2016, 116, 2478.

(2) Gilday, L. C.; Robinson, S. W.; Barendt, T. A.; Langton, M. J.; Mullaney, B. R.; Beer, P. D. Halogen bonding in supramolecular chemistry. Chem. Rev. 2015, 115, 7118.

(3) Metrangolo, P.; Resnati, G. Halogen bonding: a paradigm in supramolecular chemistry. Chem.-Eur. J. 2001, 7, 2511.

(4) Metrangolo, P.; Neukirch, H.; Pilati, T.; Resnati, G. Halogen bonding based recognition processes: a world parallel to hydrogen bonding. Acc. Chem. Res. 2005, 38, 386.

(5) Massena, C. J.; Decato, D. A.; Berryman, O. B. A long-lived halogen-bonding anion triple helicate accommodates rapid guest exchange. Angew. Chem., Int. Ed. 2018, 57, 16109.

(6) Sutar, R. L.; Huber, S. M. Catalysis of organic reactions through halogen bonding. ACS Catal. 2019, 9, 9622.

(7) Pennington, W. T.; Resnati, G.; Taylor, M. S. Halogen bonding: from self-assembly to materials and biomolecules. CrystEngComm 2013, 15, 3057.

(8) Priimagi, A.; Cavallo, G.; Metrangolo, P.; Resnati, G. The halogen bond in the design of functional supramolecular materials: recent advances. Acc. Chem. Res. 2013, 46, 2686.

(9) Eraković, M.; Cinčić, D.; Molčanov, K.; Stilinović, V. A crystallographic charge density study of the partial covalent nature of strong $\mathrm{N} \cdots \mathrm{Br}$ halogen bonds. Angew. Chem., Int. Ed. 2019, 58, 15702.

(10) Puttreddy, R.; Jurcek, O.; Bhowmik, S.; Mäkelä, T.; Rissanen, K. Very strong ${ }^{-} \mathrm{N}-\mathrm{X}^{+} \bullet \bullet \bullet^{-} \mathrm{O}-\mathrm{N}^{+}$halogen bonds. Chem. Commun. 2016, 52, 2338.

(11) Crowston, E. H.; Lobo, A. M.; Parbhakar, S.; Rzepa, H. S.; Williams, D. J. X-Ray and SCF-MO model study of the complex formed between n-bromosuccinimide and 1,4-diazabicyclo[2.2.2]octane. J. Chem. Soc. Chem. Commun. 1984, 276.

(12) Borley, W.; Watson, B.; Nizhnik, Y. P.; Zeller, M.; Rosokha, S. V. Complexes of diiodine with heteroaromatic N-oxides: effects of halogen-bond acceptors in halogen bonding. J. Phys. Chem. A 2019, $123,7113$.

(13) Weinberger, C.; Hines, R.; Zeller, M.; Rosokha, S. V. Continuum of covalent to intermolecular bonding in the halogenbonded complexes of 1,4-diazabicyclo[2.2.2] octane with brominecontaining electrophiles. Chem. Commun. 2018, 54, 8060.

(14) Rosokha, S. V.; Stern, C. L.; Ritzert, J. T. Experimental and computational probes of the nature of halogen bonding: complexes of bromine-containing molecules with bromide anions. Chem.-Eur. J. 2013, 19, 8774.

(15) Loy, C.; Zeller, M.; Rosokha, S. V. Halogen bonding in the complexes of brominated electrophiles with chloride anions: from a weak supramolecular interaction to a covalent $\mathrm{Br}-\mathrm{Cl}$ bond. Crystals 2020, 10, 1075.

(16) Bader, R. F. W. A quantum theory of molecular structure and its applications. Chem. Rev. 1991, 91, 893.

(17) Popelier, P. L. A. The QTAIM perspective of chemical bonding. The Chemical Bond; John Wiley \& Sons, Ltd., 2014; p 271.

(18) The quantum theory of atoms in molecules, from solid state to DNA and drug design; In Matta, C. F., Boyd, R. J., Eds.; Wiley VCH Weinheim, 2007.

(19) Shahbazian, S. Why Bond Critical Points are not "Bond" Critical Points. Chem.-Eur. J. 2018, 24, 5401.

(20) Espinosa, E.; Alkorta, I.; Elguero, J.; Molins, E. From weak to strong interactions: a comprehensive analysis of the topological and energetic properties of the electron density distribution involving $\mathrm{X}-$ H..F-Y systems. J. Chem. Phys. 2002, 117, 5529.

(21) Mallinson, P. R.; Smith, G. T.; Wilson, C. C.; Grech, E.; Wozniak, K. From weak interactions to covalent bonds: a continuum in the complexes of 1,8-bis(dimethylamino)naphthalene. J. Am. Chem. Soc. 2003, 125, 4259.

(22) Grabowski, S. J.; Sokalski, W. A.; Dyguda, E.; Leszczyński, J. Quantitative classification of covalent and noncovalent H-bonds. J. Phys. Chem. B 2006, 110, 6444. 
(23) Mata, I.; Alkorta, I.; Espinosa, E.; Molins, E. Relationships between interaction energy, intermolecular distance and electron density properties in hydrogen bonded complexes under external electric fields. Chem. Phys. Lett. 2011, 507, 185.

(24) Grabowski, S. J. What is the covalency of hydrogen bonding. Chem. Rev. 2011, 111, 2597.

(25) Grabowski, S. J. Non-covalent interactions - QTAIM and NBO analysis. J Mol Model 2013, 19, 4713.

(26) Grabowski, S. J. QTAIM characteristics of halogen bond and related interactions. J. Phys. Chem. A 2012, 116, 1838.

(27) Grabowski, S. J. Hydrogen and halogen bonds are ruled by the same mechanisms. Phys. Chem. Chem. Phys. 2013, 15, 7249.

(28) Quiñonero, D.; Alkorta, I.; Elguero, J. Cation-cation and anion-anion complexes stabilized by halogen bonds. Phys. Chem. Chem. Phys. 2016, 18, 27939.

(29) Scheiner, S. Systematic elucidation of factors that influence the strength of tetrel bonds. J. Phys. Chem. A 2017, 121, 5561.

(30) Bauzá, A.; Alkorta, I.; Elguero, J.; Mooibroek, T. J.; Frontera, A. Spodium bonds: noncovalent interactions involving group 12 elements. Angew. Chem., Int. Ed. 2020, 59, 17482.

(31) Thomas, S. P.; Satheeshkumar, K.; Mugesh, G.; Guru Row, T. $\mathrm{N}$. Unusually short chalcogen bonds involving organoselenium: insights into the $\mathrm{Se}-\mathrm{N}$ bond cleavage mechanism of the antioxidant ebselen and analogues. Chem.-Eur. J. 2015, 21, 6793.

(32) Frisch, M. J., Trucks, G. W.; Schlegel, H. B.; Scuseria, G. E.; Robb, M. A.; Cheeseman, J. R.; Scalmani, G.; Barone, V.; Petersson, G. A.; Nakatsuji, H.; Caricato, M.; Li, X.; Hratchian, H. P.; Izmaylov, A. F.; Bloino, J.; Zheng, G.; Sonnenberg, J. L.; Hada, M.; Ehara, M.; Toyota, K.; Fukuda, R.; Hasegawa, J.; Ishida, M.; Nakajima, T.; Honda, Y.; Kitao, O.; Nakai, H.; Vreven, T.; Throssell, K.; Montgomery, J. A., Jr.; Peralta, J. E.; Ogliaro, F.; Bearpark, M.; Heyd, J. J.; Brothers, E.; Kudin, K. N.; Staroverov, V. N.; Kobayashi, R.; Normand, J.; Raghavachari, K.; Rendell, A.; Burant, J. C.; Iyengar, S. S.; Tomasi, J.; Cossi, M.; Rega, N.; Millam, J. M.; Klene, M.; Knox, J. E.; Cross, J. B.; Baken, V.; Adamo, C.; Jaramillo, J.; Gomperts, R.; Stratmann, R. E.; Yazyev, O.; Austin, A. J.; Cammi, R.; Pomelli, C.; Ochterski, J. W.; Martin, R. L.; Morokuma, K.; Zakrzewski, V. G.; Voth, G. A.; Salvador, P.; Dannenberg, J. J.; Dapprich, S.; Daniels, A. D.; Farkas, Ö.; Foresman, J. B.; Ortiz, J. V.; Cioslowski, J.; Fox, D. J. Gaussian 09, Revision D.01; Gaussian Inc.: Wallingford, CT, 2009.

(33) Zhao, Y.; Truhlar, D. G. The M06 suite of density functionals for main group thermochemistry, thermochemical kinetics, noncovalent interactions, excited states, and transition elements: two new functionals and systematic testing of four M06-class functionals and 12 other functionals. Theor. Chem. Acc. 2008, 120, 215.

(34) Kozuch, S.; Martin, J. M. L. Halogen bonds: benchmarks and theoretical analysis. J. Chem. Theor. Comput. 2013, 9, 1918.

(35) Zhu, Z.; Xu, Z.; Zhu, W. Interaction nature and computational methods for halogen bonding: a perspective. J. Chem. Inf. Model. 2020, 60, 2683.

(36) Tomasi, J.; Mennucci, B.; Cammi, R. Quantum mechanical continuum solvation models. Chem. Rev. 2005, 105, 2999.

(37) Boys, S. F.; Bernardi, F. The calculation of small molecular interactions by the differences of separate total energies. some procedures with reduced errors. Mol. Phys. 1970, 19, 553-566.

(38) Wolters, L. P.; Bickelhaupt, F. M. Halogen bonding versus hydrogen bonding: a molecular orbital perspective. ChemistryOpen 2012, $1,96$.

(39) Lu, T.; Chen, F. Multiwfn: A multifunctional wavefunction analyzer. J. Comput. Chem. 2012, 33, 580.

(40) Humphrey, W.; Dalke, A.; Schulten, K. VMD - Visual Molecular Dynamics. J. Mol. Graph. 1996, 14, 33.

(41) Bader, R. F. W.; Carroll, M. T.; Cheeseman, J. R.; Chang, C. Properties of atoms in molecules: atomic volumes. J. Am. Chem. Soc. 1987, 109, 7968.

(42) Bondi, A. van der Waals volumes and radii. J. Phys. Chem. 1964, $68,441$.

(43) Mata, I.; Alkorta, I.; Espinosa, E.; Molins, E. Topological properties of the electron distribution in hydrogen-bonded systems. In
The quantum theory of atoms in molecules; Matta, C. F., Boyd, R. J., Eds.; Wiley-VCH Verlag: Weinheim, 2007; p 425.

(44) Cremer, D.; Kraka, E. A description of the chemical bond in terms of local properties of electron density and energy Croatica. Chem. Acta 1984, 57, 1259.

(45) Gibbs, G. V.; Cox, D. F.; Crawford, T. D.; Rosso, K. M.; Ross, N. L.; Downs, R. T. Classification of metal-oxide bonded interactions based on local potential- and kinetic-energy densities. J. Chem. Phys. 2006, 124, 084704.

(46) Gervasio, G.; Bianchi, R.; Marabello, D. About the topological classification of the metal-metal bond. Chem. Phys. Lett. 2004, 387, 481.

(47) Politzer, P.; Murray, J. S.; Clark, T. Halogen bonding: an electrostatically-driven highly directional noncovalent interaction. Phys. Chem. Chem. Phys. 2010, 12, 7748.

(48) Politzer, P.; Murray, J. S.; Clark, T. Halogen bonding and other $\sigma$-hole interactions: a perspective. Phys. Chem. Chem. Phys. 2013, 15, 11178.

(49) Wang, C.; Danovich, D.; Mo, Y.; Shaik, S. On the nature of the halogen bond. J. Chem. Theor. Comput. 2014, 10, 3726.

(50) Thirman, J.; Engelage, E.; Huber, S. M.; Head-Gordon, M. Characterizing the interplay of pauli repulsion, electrostatics, dispersion and charge transfer in halogen bonding with energy decomposition analysis. Phys. Chem. Chem. Phys. 2018, 20, 905.

(51) Huber, S. M.; Jimenez-Izal, E.; Ugalde, J. M.; Infante, I. Unexpected trends in halogen-bond based noncovalent adducts. Chem. Commun. 2012, 48, 7708.

(52) Grounds, O.; Zeller, M.; Rosokha, S. V. Structural preferences in strong anion- $\pi$ and halogen-bonded complexes: $\pi$ - and $\sigma$-holes vs frontier orbitals interaction. New J. Chem. 2018, 42, 10572.

(53) Robinson, S. W.; Mustoe, C. L.; White, N. G.; Brown, A.; Thompson, A. L.; Kennepohl, P.; Beer, P. D. Evidence for halogen bond covalency in acyclic and interlocked halogen-bonding receptor anion recognition. J. Am. Chem. Soc. 2015, 137, 499.

(54) Kellett, C. W.; Kennepohl, P.; Berlinguette, C. P. $\pi$ - Covalency in the halogen bond. Nat. Commun. 2020, 11, 3310. 